\title{
The storyline approach: a new way to analyse and improve flood event management
}

\author{
K. M. de Bruijn ${ }^{1}$ - N. Lips ${ }^{2}$ B. Gersonius ${ }^{3} \cdot$ H. Middelkoop ${ }^{4}$
}

Received: 10 June 2015/Accepted: 31 October 2015/Published online: 13 November 2015

(C) The Author(s) 2015. This article is published with open access at Springerlink.com

\begin{abstract}
Common flood risk analyses often focus on direct impacts corresponding to the maximum depths of flood events. However, this information is not sufficient for risk communication, for the design of flood emergency plans and for the selection of risk management measures. For those issues, not only a static view of the maximum flood intensity is required, but also an understanding of the sequence of events from the rise of the threat to its recovery (including the action and reaction of actors). This paper discusses a new, additional approach to support flood risk management: the storyline approach, which serves to analyse the whole sequence of events during a flood. It starts from the initial rise of the flood threat, then describes the actual flooding and ends with the recovery from the flood impacts. It shows in a structured way the most important subsystems (water system, critical infrastructure system) and actors (water managers, local authorities, critical infrastructure operators, inhabitants) and their interactions. The application of the storyline approach to Dordrecht, the Netherlands, illustrates its use not only for flood event management, but also for the analysis of critical infrastructure vulnerability. The approach is designed to be applied in workshops with all relevant actors. The storylines support the communication of what might happen and help to develop consistent flood risk management strategies and emergency plans.
\end{abstract}

Keywords Critical infrastructure - Flood event management · Flood risk management . Dordrecht · Storylines

K. M. de Bruijn

Karin.debruijn@deltares.nl

1 Flood Risk Management, Deltares, Rotterdamse weg 185, 2629 HD Delft, The Netherlands

2 Projecten Dijkversterking, Waterschap Peel en Maasvallei, Drie Decembersingel 46, 5921 AC Venlo, The Netherlands

3 Water Science and Engineering, UNESCO-IHE, Westvest 7, 2611 AX Delft, The Netherlands

4 Faculty of Geosciences, Department Physical Geography, University Utrecht, Heidelberglaan 2, 3583 CS Utrecht, The Netherlands 


\section{Introduction}

Recent flood events in, among others, Thailand (2011) (Komori et al. 2012), India (2013, 2014), (Anonymus 2015), Japan (2011) (Norio et al. 2011), the UK (2007, 2014) (Pitt 2008; Muchan et al. 2015) and Central Europe (2002, 2012) (Anonymus2 2015) show that floods still cause significant impacts. These impacts may even increase in the future due to land subsidence, climate change and socio-economic developments (IPCC 2012). The floods in Thailand, Japan and the UK showed that not only direct impacts are important, but also that indirect flood impacts can be severe and long-lasting (Impact forecasting 2012; Fuller 2011). These impacts can occur, for example, due to failure of critical infrastructure networks (CIs).

Recent events have demonstrated that flood impacts may highly depend on the sequence of actions before/during the event, such as risk and crisis communication, evacuation, critical infrastructure (CI) protection and actions taken in the recovery phase. The possibilities for such actions differ per event type: impacts of flood events with a longer lead time and duration, such as lowland river floods and coastal floods, are more likely to be mitigated by sensible actions than flash flood events. As an example, the number of fatalities might strongly depend on the number of people timely warned and the number of people evacuated (Doocy et al. 2013). The vulnerability of the critical infrastructure to flooding is also relevant for the total flood impacts, since the possibilities to survive are larger in areas with functioning critical infrastructure networks and emergency actions such as evacuation and rescue depend on the state of the roads and communication networks.

In order to reduce future impacts, flood risk management strategies are developed, which are usually based on risk analyses (see, for example, Hall et al. 2005; Kind 2013) for a situation with and without measures (Klijn et al. 2012). In these risk analyses, the probabilities of potential flood events and their impacts are combined to one aggregated risk figure. The impacts of flood events are usually analysed by translating the flood characteristics to direct flood impacts (e.g. economic damage, fatalities) by means of unitloss methods with relationships between the two (such as depth-damage curves or mortality functions). Indirect impacts, such as income losses, or production outside the flooded area is rarely considered because of their complex nature (Kreibich et al. 2014).

Despite their many advantages, commonly used risk analysis methods and the resulting risk outcomes also have several major shortcomings. Firstly, they do not provide information of the timeline or sequence of events during a flood, which is relevant for flood event managers and other actors involved during a flood. The impacts included in the risk figures are related to the 'maximum flood characteristics' during the event, such as the maximum depth and flow velocity. Secondly, the risk is an aggregate of many potential events with possibly different flood extents and water depths. Even for experts in flood risk assessment, it is difficult to imagine how one specific event will evolve or which area will be affected based on an aggregate risk figure or risk map. Flood risk figures and maps are therefore not always helpful to communicate the possibilities of mitigating actions in advance, during or after a flood. Thirdly, flood risk analyses often do not consider CIrelated impacts, which depend in a complex and indirect way on flood magnitude and inundation sequence as well as on network structure, dependencies and cascading effects. Consequently, the relation between flood intensity and impact is much more complex than assumed in so-called unit-loss methods used in traditional risk analyses. Because the effects of emergency actions and the impact on CI are rarely taken into account in flood 
risk analyses, they have received little attention in the development of flood risk management strategies.

Since modern societies depend on the well functioning of CI, they should be considered in flood risk management (all activities aiming to enable society to cope with flood risks) and flood event management (all activities related to responding to an imminent flood threat). CI comprises infrastructure that provide critical services such as transport, supply of electricity and water, and communication possibilities. These services are critical for the people in the flooded area, outside the flooded area and for emergency management. They are needed for the survival during the flooding and for the recovery after floods (Serre et al. 2011).

Establishment of adequate and realistic flood risk management thus requires insight into the timeline of flood events, role of communication and emergency actions, indirect damage and CI. Instead of using 'static' risk mapping, such analyses should consider the possible sequences of events during the incident and recovery phase. This will likely result in more efficient protection and mitigation strategies and allows revealing the most critical factors determining the final estimates of potential fatalities and damage. Such sequencebased approaches also may allow considering alternative strategies related to CI protection or spatial planning.

Therefore, we propose a new 'storyline approach' that analyses specific flood events and does not only consider the maximum flood extent/intensity and damage, but also (1) the sequence of events in advance of, during and after flooding and (2) the role of CI and its relation to the overall damage. This storyline approach is discussed in this paper.

This paper also reports on the application and initial evaluation of a storyline approach for flood risk analysis for the Island of Dordrecht, the Netherlands. This island is a typical case study of a vulnerable urbanized delta, enclosed by large river branches and under threat of coastal and river flooding. The local authorities of the Island of Dordrecht seek to develop an integrated and long-term strategy for flood risk management. The case study was undertaken in close cooperation with these actors, to establish and analyse credible storylines of flood events.

The paper first discusses the storyline approach in general, then illustrates this approach by its application for the Island of Dordrecht, and ends with a discussion on the findings, and conclusions.

\section{The storyline approach}

\subsection{Approach}

Storylines have been used in various disciplines: in social science and marketing communication, they facilitate discussion and allow establishment of coherent and meaningful summaries of data or underlying assumptions. In the field of ethnography, experiences of individuals, groups and communities are represented by means of stories. Stories provide detailed information on a subject of study, whereas a storyline is one conceptualization of a story (i.e. one narrative of one person from a community on a certain event) (Birks et al. 2009; Strauss and Corbin 1990).

In flood risk management, however, storylines and storytelling are rarely used. Two examples similar to the storyline approach were found: RWS and HKV (2008) studied a 'worst credible flood' and provided information on flood extent, damage, and fatalities at 
different moments in time. Still, this analysis did not go into detail, and the studied event was an almost unrealistically high extreme. The study focused on flood parameters and quantified impact parameters such as damage and number of fatalities. There was no description of the behaviour, actions or responses of authorities, managers or inhabitants, and it did not consider CI. The second example is the work of Haasnoot et al. (2012) who studied adaptation pathways with transient scenarios for long-term planning. They generated transient time series of climate-driven events and water management responses to establish future scenarios of impacts and responses, resulting in pathways of adaptation options. However, these pathways represented sequences of flood events occurring in the course of a century and did not focus on sequences of events during individual flood events in detail.

The storyline approach that we propose is applied for a stepwise analysis of a flood event. The approach allows to achieve a consistent set of assumptions underlying risk assessment and to increase the insight in the sequence of events during a flood event, including the responses of various involved actors. The storylines developed according to this approach describe the events during three critical phases: (1) the rising of the flood threat, (2) the flooding itself and (3) the recovery from the flooding. For each phase, the state of the water system, the functioning of CI and the flood process are described, as well as the actions and responses of the most important actors, such as the water managers, authorities, CI operators and inhabitants. The storyline approach comprises of four steps:

1. Consistent description of the system;

2. Selection of the scenarios for a storyline: A scenario includes the emergence of extremely high flood water levels and possibly a defence failure resulting in the inundation of areas protected from flooding.

3. Determination of the sequence of events during a storyline: Three phases are distinguished: preceding the flooding, during the flooding and recovery after the flooding. For each a description is made of changes in subsystems and responses and interactions among systems and actors. Such a description includes an overview of water levels, flood extent, the status of the CI and the behaviour of local authorities and inhabitants, and crisis management.

4. Analysis of the impacts of the flooding. Relevant impacts may include damage, fatalities, number of affected persons, number of houses destroyed and duration of the state of damage.

These four steps are explained below.

The first step involves obtaining a system description, which involves:

(a) Relevant water courses and flood-prone area characteristics;

(b) Critical water levels for flooding and other relevant hazard characteristics;

(c) Potential flood impacts resulting from different scenarios;

(d) CI elements and networks present in the area and their vulnerability to flooding

(e) The flood emergency management procedures and the key actors in flood event management, such as water managers, local authorities, first responders and inhabitants.

The source-pathway-receptor-consequences framework (Samuels et al. 2009) may be used to structure the information. The relevant area characteristics comprise surface elevation, land use, population density, economic activities and inherent value, location and height of levees, internal drainage network, location and characteristics of traffic and other critical infrastructure. The analysis of CI vulnerability must be included, since the 
functioning of $\mathrm{CI}$ is often crucial for efficient flood emergency management and for recovery after a flooding (see also Sect. 2.2). Finally, the existence and contents of formal procedures, protocols or standard responses of the key actors related to floods are considered. These include general early warning procedures, local warnings, evacuation calls, different actions undertaken by inhabitants according to their anticipated or experienced flooding (e.g. spontaneous evacuation and refusing to evacuate). Knowledge of these procedures is required in step 3 of the approach (storyline elaboration) to estimate correctly the behaviour and well-being of other actors and inhabitants.

In the second step, relevant storylines are selected. First, the scenarios that drive the events are selected based on the system analysis of step 1. A scenario may start, for example, by a storm surge, extreme river discharges, intensive rainfall or combinations of such events, potentially followed by a dike breach and subsequent inundation of the area. The event must be realistic and relevant. This means that it should not be a worst case that actors may think of as 'impossible', but also not an event which does not cause significant damage.

In the third step, the storyline is made, which means a subsequent detailed description of sequence of events in the advance, the flooding event itself and its aftermath. This is ideally done in collaboration with the most important actors that were identified in step 1. For each phase, the status of the water system and the functioning of the CI in the area are described, as well as the actions and reactions of the most important actors. These actors may include various types of professionals involved in emergency management such as local authorities, water boards, first responders and the inhabitants of the area.

In the fourth step, the storylines are analysed, which involves the physical changes as well as the timing and type of responses of the actors. Time series of water levels, flood inundation maps and state of $\mathrm{CI}$ at different time steps are compared with the reactions of the actors and the number of people present in flooded areas, the number of people in safe areas and the number of fatalities. This reveals the impacts of the external pressure and responses on damage and population. The impact analysis includes (a) physical damage (direct and indirect), affected CI and the wider impact, number of inhabitants affected, number of fatalities, (b) the effects of actions of local authorities and inhabitants on these impacts and (c) consequences for recovery of the area after the flood event.

Different storylines are explored and compared by varying the initial hydraulic pressure, location of dike breaches, failure or functioning of CI, and timing and nature of responses of various actors. In this way, various new flood risk management measures or adapted flood emergency procedures can be tested.

The storylines developed serve as realistic 'what if' scenarios, showing plausible potential sequences of events and behaviour of actors. The development of the scenarios will reveal the crucial uncertainties and required assumptions, which will also help flood risk managers in their work.

The next sections discuss in more detail the analysis of CI vulnerability towards flooding and the tools to support the analysis of flood hazards and flood impacts in steps 1 and 4.

\subsection{Approach to the analysis of CI vulnerability}

A critical infrastructure is an infrastructure that is essential for the functioning of society, and whose failure would seriously affect many people (Heileman et al. 2013). It includes all elements of the networks for transport, water supply and drainage, gas and power supply and telecommunication. Flood impact assessments of CI differ from general impact 
assessments. While general flood impact assessments focus on direct economic damage and most often only mention possible indirect effects, damage assessments of CI aim at assessing the indirect and secondary effects of infrastructure impairment. Direct damages to the infrastructure itself are of minor importance compared to the indirect effects of their outage. The latter include loss of income due to an electricity outage, loss of lives in hospitals due to communication interruptions, etc. and not the damage to the cables and transformation stations itself. Furthermore, the secondary effects of outage outside the flooded area and interdependencies and cascading effects to other sectors are relevant to consider (Fekete 2011). Failure of, for example, the power network may affect a wide range of other infrastructures, e.g. water supply and information technology. These effects may occur within and outside the flooded area.

Accordingly, the analysis method differs from traditional analyses. The current available methods for analysis of CI show possible effects and factors, but do not put precise monetary figures to them, as is done in general damage assessments (cf., e.g. Jonkman et al. 2008). Besides the different focus, this difference in methods is also due to limited data availability: data of CI are very difficult to obtain because it is protected for security reasons and because of competition between companies.

The vulnerability analysis of CI involves the following five steps:

(1) Network analysis: what are the network elements,

(2) Analysis of the vulnerability of network elements,

(3) Analysis of the effects of element failure on the network (resilience of network, redundancy),

(4) Effect of failure of the network to other networks: interdependency and cascading effects,

(5) Effects of outage of the networks on society.

The network analysis involves obtaining an overview of the nodes (e.g. transformer stations and transformer cabinets in the case of electricity) and connections (e.g. electricity cables in the case of electricity). The network characteristics can be described by indicators such as redundancy and centrality. Secondly, the vulnerability of each element in the network to flooding is determined and expressed by an indicator that shows the flood conditions (inundation depth) that cause damage or interruption of the CI element, as well as the recovery time required after the flood recession. In case failure of individual elements in the CI network affects the functioning of the entire network, the relationship between networks is considered. Obvious relationships exist between electricity supply and other CI: if electricity fails, pumps, communication, traffic control systems and most of the infrastructure will not function. Furthermore, failure of communication services and roads may also strongly affect the other networks. To analyse interdependencies between CI networks, various techniques are available (Lhomme et al. 2012; Ouyang et al. 2009), such as qualitative assessments (Baker 2005), mathematical modelling through network theory, agent-based methods and inoperability input-output methods. They all aim to provide insight in the structure of the networks, failure modes and finally, the criticality of the failure of certain elements or links. The final step comprises assessing the disruption of society caused by the disruption of networks. However, because quantification of this impact and associated damage is problematic, indicators such as the duration of outage, the area of outage, the number of people affected and combinations of those may be used.

Steps 1 to 3 require information from CI owners and operators, and thus their willingness and a communication modus to provide this information. Step 4 requires interaction between different CI owners. The effect of failure of CI networks on society may be 
assessed based on the information of the CI owners for varying duration of failure and estimated repair times.

\subsection{Tools to analyse flood patterns and flood impacts}

To get a full insight in the flooding and in the effect of actions of local authorities, the effects of those actions on the flood pattern, the damage, the number of affected people and the number of fatalities need to be analysed. Hydraulic flood simulation models allow determining flood propagation after dike failure and critical variables such as extent of inundated area, inundation depths, flow velocities and times of arrival of the flood water in a spatially distributed way. This can then be combined with data on land use and population density to determine the number of affected persons and potential damage. When developing the storyline, assumptions must be made on the location of the inhabitants at the onset of the flooding (e.g. at home, at work or evacuated) and how they behave. This behaviour may depend on various factors, such as the inhabitants' flood awareness, their personal knowledge of the area, evacuation/sheltering options and situation (health, age, with small children or not, etc.) and to what extent advice for certain actions was given prior to and during the event. As information on such factors is generally not readily available, it is inevitable to use rough general assumptions on these, like $80 \%$ follows the official advice of the authorities and $20 \%$ does not' to produce storylines. Storylines then reveal for those assumptions how many people are located where, how many need to be rescued, or are in need of shelter, etc. In cases where much data are available, micro-scale models such as the Life Safety Model of BC Hydro could be used to simulate the behaviour of inhabitants (Di Mauro et al. 2012; Lumbroso et al. 2010).

Damage models are used to get insight into flood impacts, such as the national damage modules (HIS-SSM for the Netherlands (Kok et al. 2005); Multicoloured Manual for the UK (Penning-Rowsell 2005); Flemo for Germany (Thieken et al. 2008; Kreibich et al. 2010); and Hazus for the USA (Scawthorn et al. 2006). The models require flood characteristics as input and translate these into economic damage figures, such as the number of affected houses and companies, identify affected roads and railroads, and indicate the number of expected fatalities. The number of people present and the flood characteristics at certain time moments resulting from the storyline are used as input for these models.

\section{Application to Dordrecht}

In order to illustrate the storyline approach and its use for flood risk management, it was applied on the island of Dordrecht. First, a system description was made by studying the physical and societal characteristics and by modelling potential flood patterns. Next, two storyline scenarios were selected and storylines were developed by researchers (the authors) based on the literature, flood simulations and interviews with emergency managers, local authorities and CI operators (Lips 2013), and then, the results were discussed in detail in workshops with all organizations and stakeholders to fill in gaps and to interact with the researchers and with each other. Based on the outcomes, a third storyline was developed with a new flood risk management strategy in place. The paper focuses on the first storyline. The second and third one are only briefly explained. Lips (2013) describes these in more detail. The next sections describe the four steps of the storyline approach: system description, selection of the scenario storylines, developing the storylines and analysis of the storyline impacts. 


\subsection{System description}

\subsubsection{Characteristics of the area}

The island of Dordrecht is located in the tidal river area of the Rhine-Meuse delta in the Netherlands. The northern part of the dike ring contains urban and industrial areas; the south is used for agriculture. The east side contains natural tidal marches. The city of Dordrecht with about 120.000 inhabitants is located in the north part of the island.

Dordrecht is threatened by flooding from high river discharges, from storm surges and combinations of both. The island has a protected part, 'the dike ring' with a flood protection designed to withstand the once in 2000 years water level, and an 'unprotected part' outside the dike ring (see Fig. 1). The unprotected areas have an elevation varying from about 0.5 to $3.5 \mathrm{~m}$ above mean sea level (msl). The protected area lies lower and has an elevation of about $0.5 \mathrm{~m}$ below msl. If flooding would occur, water depths may occur of 1.5 to even $3 \mathrm{~m}$ (Lips 2013).

\subsubsection{Flood hazards}

The flood hazard differs significantly between the protected and the unprotected part: in the unprotected part, the floods are relatively easy to forecast, flood frequency is large, flood awareness is high and especially in the urban unprotected part the potential flood depths are small. Furthermore, the flood duration is small (a few days at maximum). In the protected part, flooding is difficult to forecast since the defence strengths are uncertain, flood awareness is low, flood probabilities are very small, but potential water depths are much

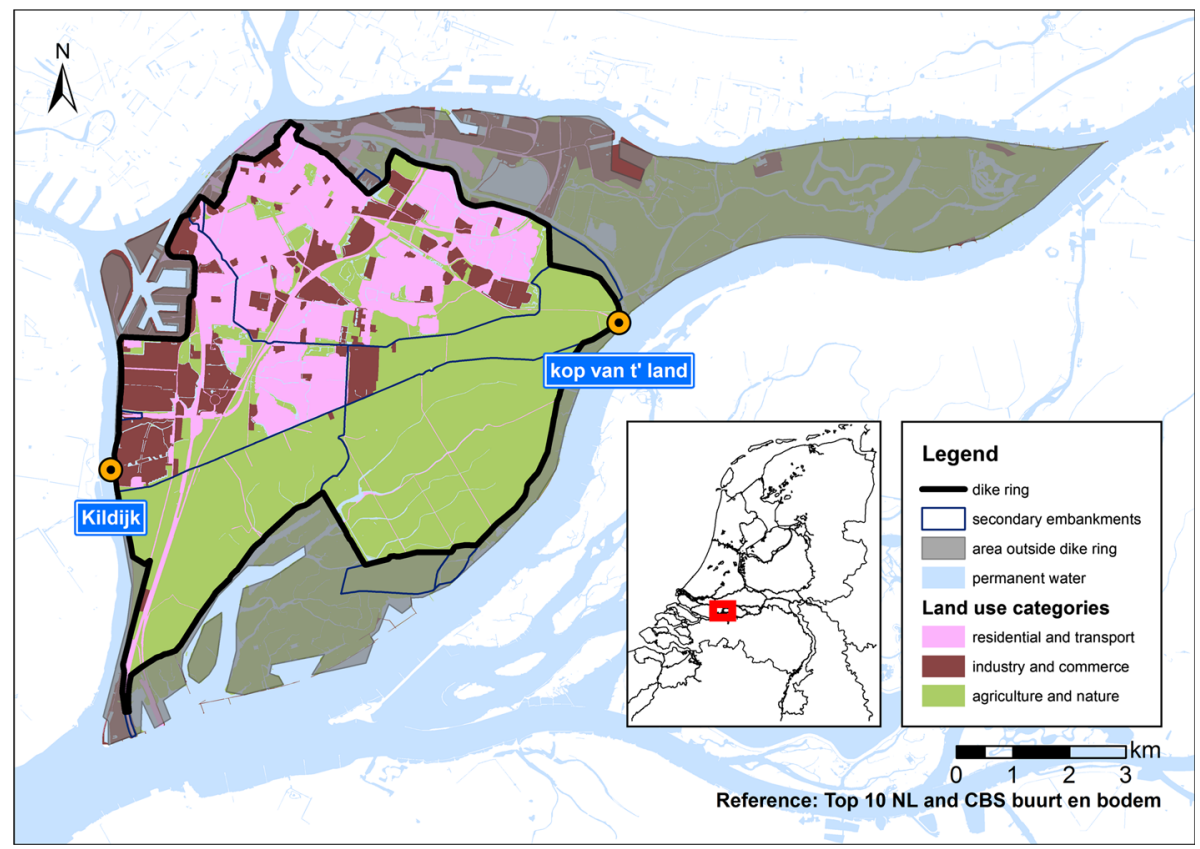

Fig. 1 Case study area 'Island of Dordrecht' 
larger than in the unprotected parts. Floods may last there for weeks, since only part of the flood water will flow out by gravity. The remaining water has to be pumped out of the area.

To obtain insight in the inundation patterns that emerge in case of a dike breach, flood simulations were carried out with a hydrodynamic model (Sobek1D2D) of the Province of South-Holland (Piek 2007). The event has a return time of 2000 years and was selected since the embankments are designed to be able to withstand events with this return time. The conditions that contribute most to the failure probability of the embankment were used, which in case of a dike breach at Kildijk (Fig. 1) is a combination of a storm surge and high river discharge. For a dike breach at the Kop van ' $t$ Land, this event is an extreme river discharge. This model includes the tidal river area and flood-prone areas. It dynamically connects a $1 \mathrm{D}$ model of the rivers, a $2 \mathrm{D}$ inundation model of the island of Dordrecht and a breach growth model. The upstream boundaries are discharge time series at the inflow location of the Meuse river and the two Rhine branches (Nederrijn and Waal) in the tidal river area. The downstream boundary is a water-level time series at the river outlet in the North Sea (Hoek van Holland). A storm surge barrier west of Rotterdam (Maeslandt) and its closure regime are included in the model. The model was developed for the Dutch Floris project (Jongejan et al. 2011), which mapped the flood risk in all floodprone areas in the Netherlands. The boundary conditions for the storylines were set equal to the scenarios that contribute most to the failure probability of the flood defences considered. The cell size of the inundation model was $100 \times 100 \mathrm{~m}$. The model is discussed in more detail in Lips (2013).

\subsubsection{Flood impacts}

Flood impacts corresponding to certain flood scenarios were assessed with the Dutch Standard Damage and Fatality model (HIS-SSM) (Kok et al. 2005). Floods in the protected area occur when the embankment breaches. Their impacts depend significantly on the precise location of the dike breach. If a breach occurs in the southeast at 'Kop van 't Land' (Figs. 1 and 2a), then the whole city of Dordrecht is flooded. This causes a damage of about 5 billion euros; it is expected to cause about 500 fatalities and affects almost 100.000 persons (Lips 2013). However, if the breach occurs in the western embankment (the Kildijk) (Figs. 1 and 2b), then only the western part of the city becomes flooded. This is expected to result in 0.8 billion euros damage, about 22.500 affected persons and 67
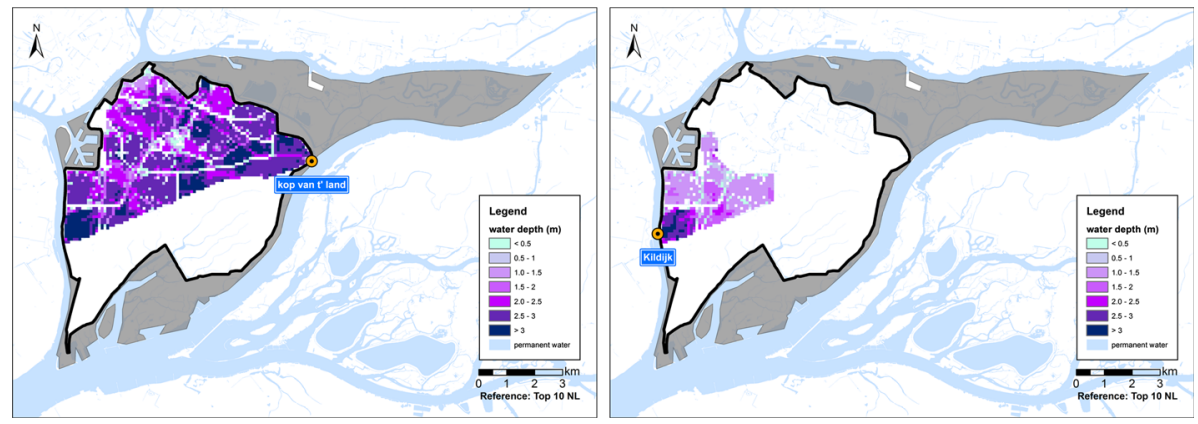

Fig. 2 Maximum water depth in the protected part due to a breach at the 'Kop van ' $t$ Land' in the east (left) and at the Kildijk in the west (right) (based on the VNK2 scenarios for the Island of Dordrecht (Piek 2007; Jongejan et al. 2011) 
fatalities. A breach in the south would cause flooding of the agricultural southern part (unless the compartmentalization dike between the northern and southern part fails, then also the northern part is at risk). In the north-west, breaches are considered highly unlikely, since the embankment there is a wide shopping street that is expected to be able to resist overtopping.

\subsubsection{Critical infrastructure}

On the island of Dordrecht, the most relevant CI is electric power supply, water supply, gas supply and transport (road and railroad network). Although all these CI networks were considered in the storyline, this paper focuses on the electricity network, because all other CI depends on electricity supply. Information on other relevant CI networks and their interaction is found in Lips (2013).

The electricity supply in the Netherlands is carried out by a high-voltage (380, 150 and $50 \mathrm{kV}$ ), medium-voltage (25 and $10 \mathrm{kV}$ ) and low-voltage (400 and $230 \mathrm{~V}$ ) network. The networks are linked at nodes by transformation stations. The Island of Dordrecht includes the $380 \mathrm{kV}$ station Crayesteijn, which is connected to other high-voltage stations in the Netherlands. On the island, there are another five high-voltage stations, 200 mediumvoltage stations and many low-voltage stations.

It is unlikely that the high-voltage power network is disrupted by flooding in Dordrecht (Lips 2013). The Crayesteijn station is located in the unprotected part, but it is raised and protected against flooding. The high-voltage network itself has a built-in redundancy and has ring-shaped layout (www.tennet.nl). Even if disruption in the functioning of Crayesteijn would occur, it is unlikely that this would cause a disruption in the network because of this redundancy. The towers and cables of the high-voltage network are flood proof.

The medium- and low-voltage network will stop functioning during a flood event. When water depths of $20 \mathrm{~cm}$ or more are forecasted, the local low- and medium-voltage electricity networks are shut down by the operator to prevent electrocution of persons (De Kort 2012). If no flooding occurs, it can be switched on again without any damage. If flooding does occur, the network will become damaged at the transformer cabinets. The low-voltage cabinets have a flood resistance of about $20-30 \mathrm{~cm}$ water depth. The medium-voltage transformers are damaged when water depths rise above $50 \mathrm{~cm}$ (Syncera 2007). It is not clear how much water pressure the electricity cables below the surface can withstand. (Syncera 2007) mentions that cables may be damaged at water depths above $50 \mathrm{~cm}$ above ground level.

The rate of repair of damaged electricity cabinets depends on the number of cabinets that must be repaired. It will take about 4 days to 12 weeks in the unprotected part of the island, where only a few streets may be affected and flood depths are generally small. Replacement of transformators delays the repair time to those 12 weeks (De Kort 2012). However, if a major embankment breaks and the area behind it becomes flooded, flood extent and depths are expected to be large. In that case, repair may take months to more than 2 years. Transformers must then be replaced, and even cables may need to be dug out and replaced (Huizinga et al. 2011).

If the electricity does not function, then the gas supply and communication networks will be disturbed as well and also the transport by car and train will face difficulties. The water supply network and water drainage network are expected to stay in function for several days, even when the power supply fails, since these have their own generators in case of power outage. 
The pumps of the water supply and water drainage network are also vulnerable to flooding, as is the road network. The disturbance of these CI networks may disrupt society on the island of Dordrecht. Crisis management and recovery will then be hampered. It is expected that damage to roads and railroads will affect also other areas outside the Island of Dordrecht. Damage to other CIs is expected to affect the island of Dordrecht only. The telecommunication network is disturbed due to the disruption of power supply in flooded areas. In non-flooded areas, communication is still possible, although it may be hampered if many areas would become flooded and all communication would have to be routed over a small number of towers.

\subsubsection{Crisis management actors}

In Dordrecht, emergency management is organized by 'the Safety Region', which is in this case headed by the mayor of Dordrecht. The safety region has a regional emergency plan for flood events (VRZHZ 2009). This plan lists river water-level forecasts that trigger action and explains the required actions. During events, a representative of the water board will be added to the safety region. The water board controls the waterways, weirs and pumps and is responsible for the flood defences. The municipality of Dordrecht has an emergency plan for flooding in the unprotected areas of the island (Gemeente Dordrecht 2012). In this analysis, we refer to the safety region, water board and municipality as 'local authorities'.

The inhabitants in the unprotected areas are generally experienced in coping with the flood threat, and, for example, placing sand bags. They are regularly informed on this threat and how they can prepare themselves. The inhabitants of the protected areas generally feel safe and are not prepared at all.

The water board and safety region obtain flood warnings from the national government. The analysis of the warnings and lead times of the warnings from the national government is based on the official flood forecasting procedures. The actions and responses of the local authorities (including the municipality, safety region and water board) are based on existing emergency plans, on discussions and personal communications with those actors and on workshop outcomes (Lips 2013).

\subsection{Selection of storylines}

The second step of the storyline approach is to select the storylines to be elaborated further. Based on the knowledge of land use and potential flood impacts, two breach locations were selected for storylines:

1. A breach along the 'Kildijk' (west side), which threatens the north-west of the island (see Fig. 2 right side)

2. A breach near the 'Kop van 't Land' (east side), which results in the flooding of the whole northern part of the island (see Fig. 2 left side).

For the first breach location, two storylines were developed: one based on the current procedures and common practice and one future one based on a situation in which shelters and other adaptations were implemented. Breaches in the northern and southern embankment are less relevant: in the south there are almost no residents, and in the north the embankment is expected to be able to resist overtopping.

The main storyline elements (systems and actors) of the storylines are:

- Water system and national water managers, 
- CI system and its operators,

- Local authorities,

- Inhabitants living outside the dike ring (in the unprotected area),

- Inhabitants living inside the dike ring (in the protected area).

The distinction between the inhabitants inside and outside the protected area was made because of the large differences in the expected hazard in both areas, in the flood experience and in the expected behaviour of both groups.

\subsection{Storyline1: a breach at the 'Kildijk'}

In the third step of the storyline approach, a storyline is elaborated for the selected scenario(s). This section discusses the first scenario: a breach at the Kildijk. Figure 3 represents the storyline in a schematic way and shows the important moments in time and the most relevant interactions. The timeline is defined in such a way that hour zero $(t=0)$ is the moment the dike breaks. The next sections describe the behaviour of the (sub) systems and actors for the three phases: the rise of the flood threat, the flooding and the recovery from the flooding. We stress again that this is a realistic but hypothetical storyline and not a description of a historic event. The indicated moments of time are derived from the flood models, the emergency procedures and warning protocols and from the expert interviews and workshops.

\subsubsection{Phase I: rise of the flood threat}

3.3.1.1 Water system and national water managers A high, but not extreme discharge ( $8000 \mathrm{~m}^{3} / \mathrm{s}$, approximately the once in 10 years discharge) occurs on the Rhine and Meuse rivers after a long period of rain in the Rhine and Meuse catchments. The river discharges and embankments along the Rhine are monitored well. When the flood wave in the river approaches the Rhine delta, a storm surge is forecasted for the coastal area. At $t=-4$ days, it becomes clear the storm will hit the Netherlands, but its intensity and precise location are not known yet. Three days later, it is predicted that the storm surge will cause water levels of about $3.5 \mathrm{~m}$ near Rotterdam, which means that the Maeslant storm surge barrier near Rotterdam is closed to protect the Rotterdam area and the densely populated and industrialized islands in the Western part of the Netherlands from the storm surge. This worsens the situation for Dordrecht, since now the river discharge to the North Sea is hampered and water levels will rise. From now onwards, it is known that the maximum water levels may reach the design water levels at Dordrecht. A first official warning is then sent out for high water levels by the national flood forecasting centre, followed by a warning for extreme water levels at $t=-21 \mathrm{~h}$. Although both river discharge and storm events are each not of extremely high magnitude, their coincidence in the same week is very rare (the probability of this coincidence is estimated at 1/2000 per year). Wind speed is expected to be high, but not extreme (9 Beaufort). Seventeen hours before the breach, the quays and streets in the unprotected areas of the city become flooded. At time $t=0$, the embankment along the Dordtse Kil at the western side of the island breaks.

3.3.1.2 Critical infrastructure The high-voltage $380 \mathrm{kV}$ station Crayesteijn located in the unprotected area is monitored carefully, but does not become flooded. Electricity and other CI are still functioning normally. Only the roads in the unprotected inner city have been closed, and the most vulnerable sewer districts are shut off. The main roads are not flooded. 


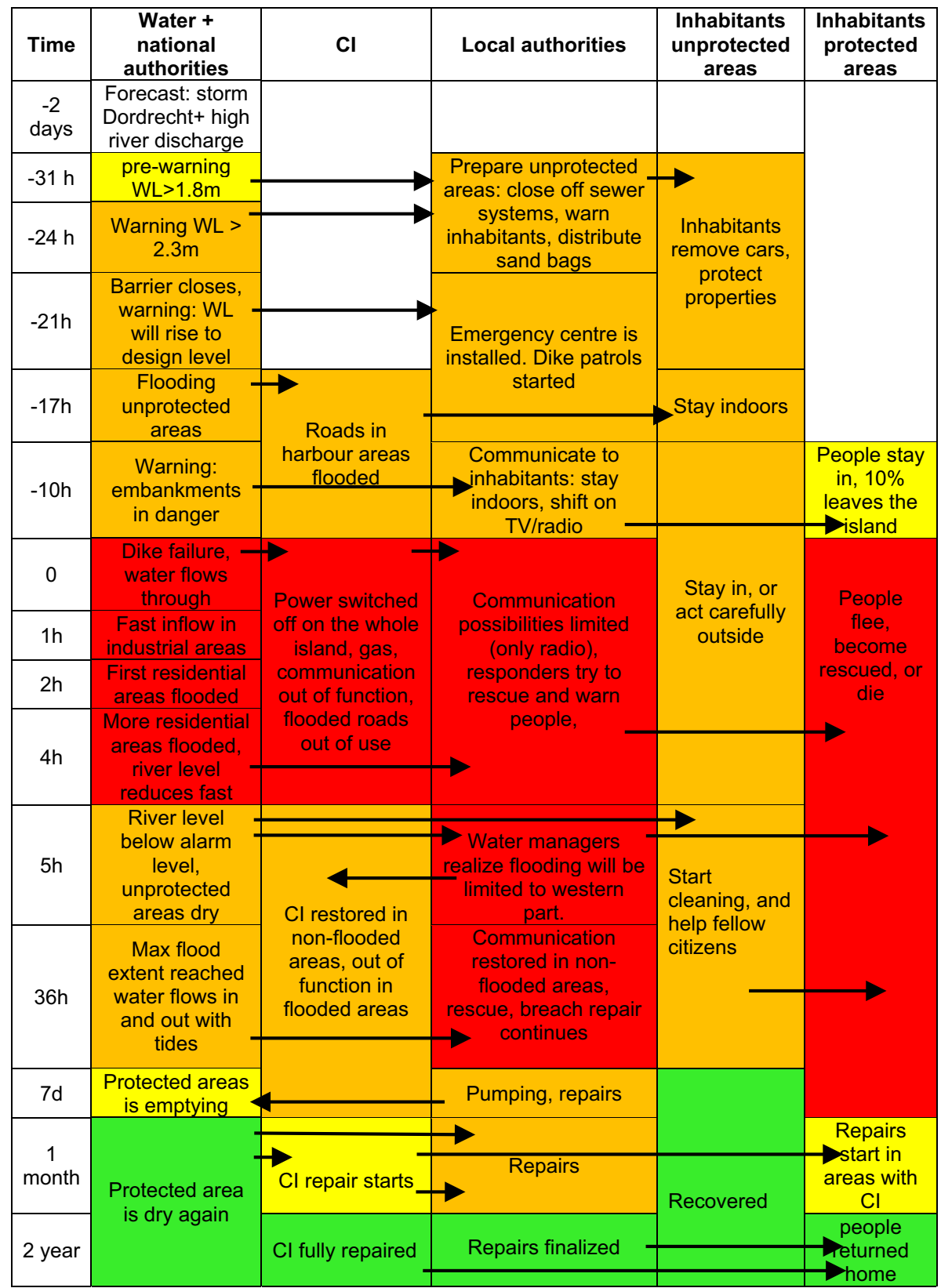

Fig. 3 Time line showing the most important time moments, events and interactions of the storyline. A column is yellow when systems or actors are alerted, orange when actions are required and red during crisis. The column turns green after recovery. The next sections provide further details

3.3.1.3 Local authorities The local authorities follow the water-level forecast. At $t=-2$ days, they start to warn the people in the unprotected areas and deliver them sand bags, and carry out emergency plans according to the normal routines. After the first 
warning, they start monitoring the water levels and flood defences. When the Maeslant storm surge barrier closes and the second warning is issued by the national water managers, the water board occupies the action centre and starts up the system of intensive monitoring of the embankments and water levels. All demountable water defences in the city are now closed as well. At time is $-10 \mathrm{~h}$, it becomes clear that there is a realistic flood hazard for the protected area. The authorities decide to give the advice not to evacuate, because they expect that evacuation is not possible anymore. Traffic is hampered by the storm and not only Dordrecht is at risk, but also the surrounding dike rings. All these areas are densely populated, and the capacity of the exit roads is limited. Local authorities communicate to the inhabitants: "There is a flood threat at our island and the surrounding areas in the delta. Please stay indoors and switch on the radio or television".

3.3.1.4 Inhabitants of the unprotected areas The inhabitants living in the unprotected part outside the dike ring protect their property by sand bags, evacuate their cars and other valuables and go inside. Some streets become flooded, but depths remain below $50 \mathrm{~cm}$ above ground level, and most houses stay dry indoors.

3.3.1.5 Inhabitants of the protected area The inhabitants living inside the protected area receive the warning and advice from the municipality. They have never encountered such a situation before. About $90 \%$ of the inhabitants behave as told and go inside. However, $10 \%$ of the inhabitants try to evacuate by private car, despite the bad storm. They manage to reach safe areas. However, there are still more than 100.000 persons left on the Island of Dordrecht (incl. the unprotected areas) when the dike breaks.

\subsubsection{Phase II: flooding}

3.3.2.1 Water system and flooding Due to the dike breach at the Kildijk, water flows into the low-lying polder area with large force. About $1 \mathrm{~h}$ after the breach the first industrial area is flooded, after $2 \mathrm{~h}$ the first residential area becomes flooded and after $4 \mathrm{~h}$ the water flows over the area as shown in Fig. 4, and water continues flowing in. The resulting flood propagation is derived from the flood simulations (Piek 2007; Jongejan et al. 2011). The water level in the river lowers in the hour after the breach, due to the lowering of the tide, the opening of the Maeslant barrier after the storm, and the recession of the discharge wave. Five hour after the breach water levels are below the warning level again, and it becomes clear that the other embankments will hold. The maximum water level in the flooded area is reached after $36 \mathrm{~h}$. The flooding then has affected both industrial and residential areas. From that point onwards, water starts flowing in and out through the breach with the rise and fall of the tide. The water boards have managed to close off local water systems that may have otherwise distributed the flood water across secondary embankments to other parts of the island and closed openings in compartmentalization embankments. The flood is therefore limited to the western part of the island, which is a crucial assumption in this storyline (Fig. 3).

3.3.2.2 Critical infrastructure Immediately when the breach occurred, the CI operators were warned by the water board and switched of the power supply at all areas on the island that were at risk. This means that communication is seriously affected and that heating of buildings stops. After a while, when it becomes clear that the other embankments will hold and that the centre of the city will not become flooded, power supply is restored in the 
eastern part of the island. Fortunately, the electricity system layout is such that this area can be switched on independently from the western side of the island. Only in the flooded area power supply is still switched off then. Furthermore, the roads in the flooded area are not accessible anymore, which also hampers the crisis management. Finally, many relevant CI networks in the flooded area such as power supply, water supply, gas supply, transport and communication networks are out of function. However, in the non-flooded parts of the island, these CI networks continue to function.

3.3.2.3 Local authorities The local authorities face now difficulties in communication because all power supply was switched off initially and they behave less efficient. They try to safe people, to repair embankments, to prevent further flood spreading and to reduce damage. If they reach people in the flooded buildings, their message is: stay in, wait for rescue. The army is called into rescue people. Many people are rescued by small boats that transport them to dry locations.

3.3.2.4 Inhabitants of the unprotected areas The inhabitants in the unprotected areas survive the first day, then the water drops again and they start cleaning and recover. They also reach out to the people in the flooded area, offer them shelter and help them to survive.

3.3.2.5 Inhabitants of the protected areas The inhabitants of the protected areas face a more difficult situation. In the flooded area, about 18.000 people are still trapped in houses without communication, electricity, heating or food supply. Floods occur in wintertime when temperatures in the Netherlands are often below $5{ }^{\circ} \mathrm{C}$. Some people left in time,

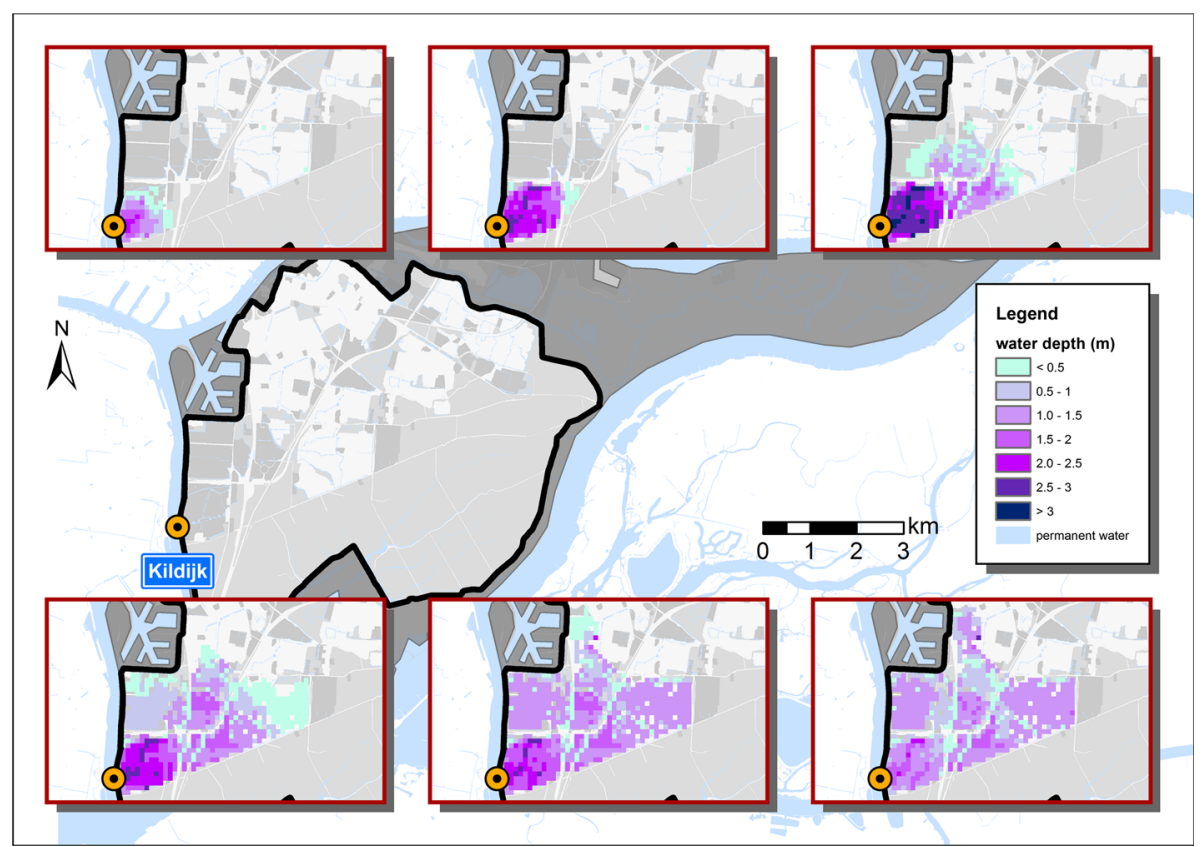

Fig. 4 Flood propagation at 1, 2, 4, 8, 16 and $32 \mathrm{~h}$ after the initiation of the breach (derived from the VNK2 breach scenario of the breach at Kildijk at design conditions) (Piek 2007; Jongejan et al. 2011) 
when they heard the embankment broke. Many people try to get away or to become rescued in the next 2 days. And about 67 people die (out of the 20.000 inhabitants of the flooded area) (Lips 2013). About two to 3 days after the breach occurred, all people are rescued (according to the local authorities estimates).

\subsubsection{Phase III: recovery}

Finally, after a week the breach is repaired (this rate was assumed based on historic data and the fact that only one breach occurred in the Netherlands in this storyline, if more breaches must be repaired, then the repair time may be longer). The water flows away and is pumped out within about 1 month. After that, cleaning and repair of the area start and CI is repaired. Slowly the damage is repaired, schools and other institutes re-open and people return to their homes. How the recovery phase must be organized or can be arranged was not studied in detail. It was estimated to last between 3 months and multiple years (Lips 2013).

\subsection{Storyline 2: a breach at Kop van 't Land}

The second storyline involves a breach in 'Kop van 't Land' due to an extreme Rhine River discharge that equals the design discharge. It is described in detail by Lips (2013). In this storyline, the Rhine discharge is higher than ever recorded, which means that many areas along the Rhine River in Germany and the Netherlands had to be evacuated and emergency measures were taken to strengthen the Rhine embankments. In this situation, the advice to the inhabitants of the island of Dordrecht to evacuate came, but late and then evacuation traffic from other flood-prone areas hampered evacuation further. Fortunately, the Rhine embankments held in the whole upstream area of Dordrecht and also in the neighbouring upstream dike rings.

However, in this storyline the embankment along Dordrecht breaks at the worst location imaginable. Only about $20 \%$ of the people has left the area before the dike breaks. When the dike breaks, power supply stops and communication, traffic management systems, traffic lights and street lights all stop functioning and in the dark, chaos starts while the area becomes flooded deeply. Emergency managers feel powerless without means of communication, electricity and without realistic options or advices. They know that if people are not evacuated before the flooding, it will become difficult to get them all out in time (deep flood water, no power supply, no normal communication means and 120,000 people in need of help). Still many people manage to get out before the flood water reaches them. The flooding affects all residential areas in the protected part, and these areas face large water depths (up to $3.3 \mathrm{~m}$ ). This means that sheltering on the island is no option. About 500 persons die and also the damage is very high. Recovery takes a long period of time since the CI networks are damaged severely and the number of affected houses and objects is very large. It takes more than a year before most people return to their homes.

\subsection{Developing a storyline for an improved situation}

For two breach locations, storylines were developed (see Sects. 3.3 and 3.4). The first one was most interesting because it shows the potential effects of actions and reactions of the actors and the interdependence of the different systems. The second one, a breach at 'Kop van 't Land', represents a more devastating, but less interesting event, since a breach there 
would result in rapid and deep flooding of the most important part of the island, including the city itself. Emergency managers are rather powerless in such situation. The sequence of events and the reactions of the different stakeholders have less influence on the consequences of the flooding than in the first storyline (see Sect. 3.4 and Lips 2013).

The storylines were first developed by scientists based on the literature, model calculations and interviews with stakeholders. Then, they were discussed with all stakeholders in a workshop and improved by information exchange between the scientists and stakeholders and among the stakeholders. The workshop with all actors on the two storylines resulted in the following observations and proposals for flood risk management:

- A breach at 'Kop van 't Land' is disastrous and leaves little options for sheltering, evacuation and emergency management. This severe scenario corresponds with a breach in a short dike stretch around the 'Kop van 't Land'. Because the municipality considered this scenario as a scenario that must be prevented at high costs, they proposed to the national government to strengthen this short dike stretch beyond the economic optimal level and to make it flood 'overtopping resistant'.

- A breach in the west is serious, but the impacts can be mitigated by sensible emergency management actions. For example, sheltering and evacuation will reduce the loss of life significantly. The local authorities proposed to develop better emergency plans to be prepared for breaches in that embankment. They include the advice to send people to shelters on the island itself (since now they know the east part may be kept dry), and they prepare closure of the compartmentalization embankments and regional waterways in order to limit the flooding to the western part of the island.

- In the north, breaches are unlikely, while in the south they do not affect urban or residential areas (assumed that the ancient sea defence which separates the north and south will hold).

A third storyline was developed based on these observations and ideas. This storyline focuses on the same breach location as the first storyline, but now with shelters and adequate emergency plans in place. Besides, the water board is now prepared to take actions to limit the flooding to the western part. This knowledge enables them to give a clear and convincing advice, while in the past (storyline 1) they were not sure whether the eastern part would become flooded or not. This makes evacuation more feasible and enables the event managers to communicate a clearer message.

In the third storyline, the water system and national warnings are the same as in the first storyline. The flood pattern is also the same. However, since now the proposed measures have been implemented, the authorities and other actors are better prepared and know what might happen. The western residential areas are the only residential areas which still have a flood risk, since the eastern embankment is now overtopping resistant, and floods in the southern part only affects the agricultural area (the compartmentalization embankments are supposed to be strengthened). The flood pattern corresponding to breaches at the west side of the island is less uncertain now: preparations were made to enable to prevent water from flowing to the east side of the island. The water boards prepared all actions needed to close openings in compartmentalization embankments and the regional water system in order to limit the flood pattern. The emergency managers now know that the communication will fail in case of flooding and in the storyline they advised the inhabitants already before the breach occurs. They tell them to evacuate to the city shelters in the east or to relatives or friends in that area. Local authorities reach $80 \%$ of the inhabitants. After the dike breaks, the emergency managers immediately drive through the residential areas to warn and pick up the people left behind and bring them to the eastern side of the island. During the flood event, no fatalities occur. 


\subsection{Analysis of the storylines}

In the fourth step of the storyline approach, the storylines were analysed. The damage and fatalities corresponding to the different flood events were assessed with the Dutch Standard Damage and Fatality model (Kok et al. 2005). The evacuation success rate (the percentage of people who may be evacuated before the onset of the flooding) and the percentage of people present in the flooded area were assessed by comparing the time available to evacuate from the moment of warning or of breaching (depending on the storyline) to the arrival of the first flood water and the time needed to get to safe areas. It was assumed that people leave $1 \mathrm{~h}$ after they are told to leave and travel $4 \mathrm{~km} / \mathrm{h}$ on foot or $20 \mathrm{~km} / \mathrm{h}$ by car in non-flooded areas. They do not leave flooded areas. Safe areas may be on the island at less than $5 \mathrm{~km}$ from their house (storyline 1) or somewhere else in the Netherlands (storyline 2). Different assumptions were used for the self-reliant and non-self-reliant persons: the non-self-reliant persons evacuated already before the dike broke. The number of non-self-reliant inhabitants per neighbourhood was taken from CBS neighbourhood files (http://www.opencbs.nl/). The assumptions were made for evacuation speed, rescue rate of people from flooded houses, and pump capacity to calculate the time to drain the water which is not flowing out by gravity $\left(583 \mathrm{~m}^{3} / \mathrm{min}\right.$, which is the total capacity of the pumps on the island), and these were discussed with experts and crisis management organizations.

Table 1 provides an overview of the outcomes of the analysis of the storylines. It summarizes the damage, number of fatalities and affected persons. It also shows that if in a future flood risk management strategy for the island events corresponding to storyline 2 could be prevented and if storyline 1 would be turned into storyline 3 events, the island would be much safer. For a proper consideration of measures and strategies, also a cost analysis and a full risk analysis are required.

\section{Discussion}

\subsection{Observations about the case study Dordrecht}

In the development of the storylines, many uncertain choices and assumptions were made. In the workshops, uncertainties were discussed and also their influence on actions was considered. The most uncertain factors were: behaviour of inhabitants and authorities (they

Table 1 Damage (price level of 2000) and number of affected inhabitants for the three storylines (Lips 2013)

\begin{tabular}{|c|c|c|c|c|c|c|}
\hline \multirow[t]{2}{*}{ Storyline } & \multirow{2}{*}{$\begin{array}{l}\text { Direct } \\
\text { damage } \\
(\mathrm{M} €)\end{array}$} & \multicolumn{5}{|c|}{ Number of persons } \\
\hline & & $\begin{array}{l}\text { Inhabitants } \\
\text { flooded } \\
\text { area }\end{array}$ & $\begin{array}{l}\text { Evacuated } \\
\text { before breach } \\
\text { initiation }\end{array}$ & $\begin{array}{l}\text { Leaving after breach } \\
\text { initiation, before } \\
\text { arrival of water }\end{array}$ & $\begin{array}{l}\text { Rescued out } \\
\text { from flooded } \\
\text { areas }\end{array}$ & Fatalities \\
\hline $\begin{array}{l}\text { 1. Western } \\
\text { breach }\end{array}$ & 700 & 20,000 & 0 & 2000 & 18,000 & 70 \\
\hline $\begin{array}{l}\text { 2. Eastern } \\
\text { breach }\end{array}$ & 4684 & 120,000 & 24,000 & 50,000 & 45,500 & 566 \\
\hline $\begin{array}{l}\text { 3. As } 1 \text {, } \\
\text { with } \\
\text { adaptation }\end{array}$ & 700 & 20,000 & 18,000 & 2000 & Few & - \\
\hline
\end{tabular}


are not used to these circumstances), the strength of local obstructions (e.g. elevated roads) and ancient embankments and their effect on the flood pattern, the CI resistance and resilience and interdependence, the effect of non-considered events and actors (chemical industry, social media, press) and the effect of the surrounding areas on Dordrecht. If Dordrecht is threatened, the nearby dike ring areas will also face a flood threat. If they evacuate, the people of the other areas may drive across the island of Dordrecht. If the other areas become flooded, help from, for example, the army may have difficulties to reach Dordrecht. Because of these uncertainties, the storylines should be regarded as examples, and not as predictions.

The storylines were discussed with the actors, local authorities (municipality, safety region, water board, electricity operator, water supply company, etc.) and elaborated further in workshops. These workshops showed the use of the storyline for communication. The emergency managers, for example, now clearly faced at a certain stage that they had to continue without power supply and their normal communication means. The water board recognized the need to close off the regional water ways and to close off opening in compartmentalization embankments to stop the water from flowing from the western to the eastern part of the island, where the largest part of the city of Dordrecht is located. The CI network operators and authorities were relieved to find out that the city may be expected to still have power, gas and water supply, even if the western part of the island becomes flooded. They did not know it was possible to limit the flooding to the western part of the island. Even without having all data on the CI network, both CI network owners and the local authorities (emergency managers, water board, and municipality) could obtain a clear view of what infrastructure functions would become disrupted in different flood scenarios. They could also together prioritize measures, such as dike strengthening (at the dangerous east side), developing emergency plans and shelters (in case of a breach at the west side), and maintaining and improving the compartmentalization dike between the south and the north. The storylines thus contributed to the development of both consistent flood event management plans and a consistent flood risk management strategy.

It was found that coordinating actions in flood event management related to CI are difficult. There is no exchange of data for security, commercial and financial reasons. No single organization is responsible for coordinating the organizations involved in FRM related to CI. The Dordrecht case showed that contacts between network operators and flood event managers are crucial, both in the preparation phase and in time of crisis. To reduce the vulnerability of CI towards floods and the effects of CI damage on flood risks, it is advised to take flood risks into account in all new developments of $\mathrm{CI}$ in the unprotected areas (the network owners could do that), to include CI operation in emergency plans and to design regulations for $\mathrm{CI}$ which requires the consideration of flood hazards. The regulations may be differentiated based on the criticality of the CI and the flood probability of the area.

\subsection{Observations about the storyline approach}

The storyline method was developed as an additional flood risk analysis approach next to the more generally applied flood risk analyses. It has some important advantages:

- It provides a clear mutual basis for discussion on what may happen and what could be done.

- One specific scenario is easier to comprehend than an aggregate risk figure, and it is easier to link actions to the specific scenario. Of course, the scenario must be selected 
carefully from the whole set of possible flood events. It should be realistic, representative and relevant for flood emergency managers. It does not need to be the 'worst possible' event.

- The storylines point to interdependencies and complexities between the water system, $\mathrm{CI}$ and actors.

- The storyline approach allows analysis of CI in relation to flood event management, recovery and local protection measures.

- Data of CI do not need to be provided to flood managers. Information can be shared in confidential workshops.

- The storyline approach provides insight on which assumptions are relevant and helps to identify knowledge gaps.

- The storyline may also serve to communicate with other stakeholders than the ones present in workshops, such as civilians, national authorities or local industries or companies.

- The storyline approach provides input for the analysis of indirect effects by providing insight on impacts of the flooding on critical infrastructure and on the duration of the flooding and the recovery afterwards (although in the storylines discussed here this was only addressed roughly estimated).

The approach is not applicable in all situations and also has some drawbacks and challenges. These are:

- The approach is time-consuming: it requires interviews with different stakeholders and may involve research of small details, which may be crucial for the sequence of events.

- The workshop successes depend on the people present and their knowledge.

- The approach depends on careful selection of the storylines. This must be done by people with an overview of the area and flood risk management issues. The selected storylines must be realistic, meaningful and include the most relevant events.

- The approach is not feasible for the risk comparison of different areas. The approach thus adds to more commonly used flood risk analyses, but does not replace these.

- The rate of inundation progress is uncertain and depends on several assumptions. This must be made clear by the flood modellers to all actors involved.

Considering the above points, the method seems more difficult to apply to larger areas where many flood scenarios are possible and where many different actors and stakeholders are present.

\section{Conclusions}

This paper discussed the storyline approach and illustrated it by an application for flood risk analysis for the island of Dordrecht. The storyline approach has a clear added value for flood risk management next to more traditional flood risk analyses. It forces analysts to make explicit descriptions of the timeline of the flood threat, the effects on the water levels, the flood patterns, the CI state and the actions and reactions of the most important actors. This reveals the most crucial moments, locations, actions and knowledge gaps. This knowledge of the sequence of events before, during and after a flooding supports actions and plans and thus flood risk management.

The approach also enables the consideration of the effect of floods on CI and the effects of CI disruption on flood event management. Its application to Dordrecht showed that the 
outage of power supply is particularly important, since it leads to the disruption of services of other CI (communication, traffic information systems, traffic lights, etc.). All these CIs are crucial for crisis management and recovery. In the case of Dordrecht, the CI network functioning was found to be not very vulnerable to floods. The functions were disrupted only in the flooded areas, while CI disruption in the other areas was limited to disruption in the transport sector.

The application of the storyline approach in workshops brings together a range of diverse disciplines and actors, such as flood modellers, crisis managers, rescue teams, water boards and municipalities. The involvement of CI operators in crisis management and flood risk management increases efficiency of emergency management. It was found that the approach helps to communicate potential impacts and measures to all actors and to underpin choices for strategies and measures.

Acknowledgments The research was supported by the municipality of Dordrecht and financed by FloodProbe project of the European Community Seventh Framework Programme for European Research and Technological Development (2009-2013).

Open Access This article is distributed under the terms of the Creative Commons Attribution 4.0 International License (http://creativecommons.org/licenses/by/4.0/), which permits unrestricted use, distribution, and reproduction in any medium, provided you give appropriate credit to the original author(s) and the source, provide a link to the Creative Commons license, and indicate if changes were made.

\section{References}

Anonymus (2015) 2010 Pakistan floods. From Wikipedia, the free encyclopaedia. https://en.wikipedia.org/ wiki/2014_India\%E2\%80\%93Pakistan_floods

Anonymus2 (2015) 2013 European floods. From Wikipedia, the free encyclopaedia. https://en.wikipedia. org/wiki/2013_European_floods

Baker GH (2005) A vulnerability assessment methodology for critical infrastructure sites. Department of Homeland Security Symposium: R\&D Partnerships in Homeland Security, Boston

Birks M, Mills J, Francis K, Chapman Y (2009) A thousand words paint a picture: the use of storyline in grounded theory research. J Res Nurs 14(5):405-417. doi:10.1177/1744987109104675

De Kort R (2012) Kwetsbaarheid in het buitendijks gebied. Analyse van de gevolgen van overstroming op vitale infrastructuur en stedelijke functies in Rotterdam. Gemeente Rotterdam, Rotterdam (In Dutch)

Di Mauro M, De Bruijn KM, Meloni M (2012) Quantitative methods for estimating flood fatalities: towards the introduction of loss of life estimation in the assessment of flood risk. Nat Hazards. doi:10.1007/ s11069-012-0207-4

Doocy S, Daniels A, Murray S, Kirsch TD (2013) The human impact of floods: a historical review of events 1980-2009 and systematic literature review. PLoS Curr Disasters. doi:10.1371/currents.dis. f4deb457904936b07c09daa98ee8171a

Fekete A (2011) Common criteria for the assessment of critical infrastructures. Int J Disaster Risk Sci 2(1):15-24

Fuller T (2011) Thailand flooding cripples hard-drive suppliers. New York Times, New York

Gemeente Dordrecht (2012). Hoogwater Bestrijdingsplan. Gemeente Dordrecht, Dordrecht (In Dutch)

Haasnoot M, Middelkoop H, Offermans A, Van Beek E, Van Deursen WPA (2012) Exploring pathways for sustainable water management in river deltas in a changing environment. Clim Change. doi:10.1007/ s10584-012-0444-2

Hall JW, Sayers PB, Dawson RJ (2005) National-scale assessment of current and future flood losses. Nat Hazards 36(1-2):147-164

Heilemann K, Balmand E, Lhomme S, De Bruijn KM, Nie L, Serre D (2013) Identification and analysis of most vulnerable infrastructure in respect to floods. Distribution Flood ProBE Consortium, Flood probe report number WP2-01-12-04

Huizinga J, Nederpel A, De Groot K, Batterink M (2011) Risicomethode buitendijks: Methodiek ter bepaling van risico's als gevolg van hoog water. Provincie Zuid Holland, Arcadis, HKV lijn in water, Lelystad (In Dutch) 
Impact Forecasting (2012) 2011 Thailand floods, event recap report. Impact forecasting, Aon Benfield, Chicago, USA. http://thoughtleadership.aonbenfield.com/Documents/20120314_impact_forecasting_ thailand_flood_event_recap.pdf

IPCC (2012) Summary for policymakers. In: Field CB, Barros V, Stocker TF, Qin D, Dokken DJ, Ebi KL, Mastrandrea MD, Mach KJ, Plattner GK, Allen SK, Tignor M, Midgley PM (eds) Managing the risks of extreme events and disasters to advance climate change adaptation. A special report of working groups I and II of the intergovernmental panel on climate change. Cambridge University Press, Cambridge and New York, pp 1-19

Jongejan R, et al. (2011) The VNK2 project: a detailed, large-scale quantitative flood risk analysis for the Netherlands. In: Proceedings of the 5th international conference on flood management (ICFM5), 27-29 Sept 2011, Tokyo

Jonkman SN, Bočkarjova M, Kok M, Bernardini P (2008) Integrated hydrodynamic and economic modelling of flood damage in the Netherland. Ecol Econ 66(2008):77-90

Kind JM (2013) Economically efficient flood protection standards for the Netherlands. JFRM. doi:10.1111/ jfr3.12026

Klijn F, De Bruijn KM, Knoop J, Kwadijk J (2012) Assessment of the Netherlands' flood risk management policy under global change. Ambio. doi:10.1007/s13280-011-0193-X

Kok M, Huizinga HJ, Vrouwenvelder AC, Van den Braak WEM (2005) Standaardmethode 2005. Schade en slachtoffers als gevolg van overstromingen. Rapport 999.10, HKV Lijn in Water, Lelystad (In Dutch)

Komori D et al (2012) Characteristics of the 2011 Chao Phraya River flood in Central Thailand. Hydrol Res Lett 6:41-46. doi:10.3178/HRL.6.41

Kreibich H, Seifert I, Merz B, Thieken A (2010) Development of FLEMOcs-a new model for the estimation of flood losses in the commercial sector. Hydrol Sci J 55(8):1302-1313

Kreibich H, van den Bergh JCJM, Bouwer LM, Bubeck P, Ciavola P, Green C, Hallegatte S, Logar I, Meyer V, Schwarze R, Thieken AH (2014) Costing natural hazards. Nat Clim Change 4(2014):303-306

Lhomme S, Serre D, Nie L, Balmand E, Heileman K, De Bruijn KM (2012) A stepwise approach for flood risk and vulnerability assessment for urban flood critical infrastructures. In: FLOODRISK 2012 conference, Novemb 2012, Rotterdam

Lips N (2013) Application of storylines for strategy development in flood risk management (FRM). A case study on the flooding of the island of Dordrecht (the Netherlands). Msc Thesis, Utrecht University, The Netherlands

Lumbroso DM, Johnstone W, De Bruijn KM, Di Mauro M, Lence B, Tagg A (2010) Modelling mass evacuations to improve the emergency planning for floods in the UK, the Netherlands and North America. Presented at the international conference on emergency preparedness (InterCEPt), the challenges of mass evacuation, 21-23, Sept 2010, University of Birmingham, UK

Muchan K, Lewis M, Hannaford J, Parry S (2015) The winter storms of 2013/2014 in the UK: hydrological responses and impacts. Weather 70:55-61. doi:10.1002/wea.2469

Norio O, Ye T, Kajitani Y, Shi P, Tatano H (2011) The 2011 Eastern Japan great earthquake disaster: overview and comments. Int J Disaster Risk Sci 2(1):34-42. doi:10.1007/s13753-011-0004-9

Ouyang M, Hong L, Mao ZJ, Yu MH, Qi F (2009) Simulation modelling practice and theory. A methodological approach to analyze vulnerability of interdependent infrastructures. Simul Model Pract Theory 17(5):817-828

Penning-Rowsell EC, Johnson C, Tunstall S (2005) The benefits of flood and coastal risk management: a manual of assessment techniques. Middlesex University Press, London

Piek R (2007). Hydraulische Randvoorwaarden Overstromingsscenario's VNK-II Provinciale Risicokaart Provincie Zuid-Holland 1e concept. PZH-2007-336478. Den Haag, The Netherlands (In Dutch)

Pitt M (2008) Learning lessons from the 2007 floods. Cabinet Office, London

RWS (Rijkswaterstaat), HKV lijninwater (2008) Overstromingsscenario's voor rampenplannen; Benedenrivierengebied. Rijkswaterstaat, Lelystad (In Dutch)

Samuels P, Gouldby B, Klijn F, Messner F, Van Os A, Sayers P, Schanze J, Udale-Clark H (2009) Language of risk-project definitions. EU Floodsite Report T32-04-01, 2nd edn. HR Wallingford, UK

Scawthorn C, Flores P, Blais N, Seligson H, Tate E, Chang S, Mifflin E, Thomas W, Murphy J, Jones C, Lawrence M (2006) HAZUS-MH flood loss estimation methodology. ii. damage and loss assessment. Nat Hazards Rev 7:72-81 (Special Issue: multihazards loss estimation and HAZUS)

Serre D, Lhomme S, Heilemann K, et al (2011) Assessing vulnerability to floods tof the built envrionment. Integrating urban networks and buildings. In: Ayyub, B. M. (2011). Vulnerability, uncertainty, and risk: analysis, modeling, and management. ASCE, USA, pp 746-753. doi:10.1061/41170(400)91

Strauss AL, Corbin JM (1990) Basics of qualitative research: grounded theory procedures and techniques. Sage publications, Newbury Park 
Syncera BV (2007) Quick scan Halve meter ramp. In opdracht van V\&W and DG- water. Project number: W06A0243. Delft, The Netherlands (In Dutch)

Thieken AH, Olschewski A, Kreibich H, Kobsch S, Merz B (2008) Development and evaluation of FLEMOps-a new flood loss estimation model for the private sector. WIT Trans Ecol Environ 118:315-324

Veiligheidsregio Zuid Holland Zuid (VRZHZ) (2009) Regionaal Basisplan Overstromingen Zuid Holland Zuid; specifiek deel dijkring 22, Eiland van Dordrecht. Versie: RBO ZHZ v2.7, Dordrecht (In Dutch) 